Comparative Philosophy Volume 3, No. 2 (2012): 10-15

Open Access / ISSN 2151-6014

www.comparativephilosophy.org

CONSTRUCTIVE ENGAGEMENT DIALOGUE (1.2)

\title{
WELL, YES AND NO: A REPLY TO PRIEST
}

\section{KRISTIE DOTSON}

It is rare to have an occasion to discuss one's ideas with an interlocutor with the generosity and rigor of Graham Priest. I have genuinely enjoyed our exchange and how Priest has pushed me to clarify the scope of my analysis. In contemplating Priest's reply and our informal correspondence, it has become clear to me that Priest and I share a great many ideas and orientations. For example, we both appear to be allergic to orthodoxy, i.e. gate-keeping that does not let in all "legitimate traders" [4] $]^{1}$. So, yes, it would seem that we both hold a concern that professional philosophy has an unpleasant proclivity towards the development and sustenance of orthodoxy. And, I assume, we are both committed to contributing towards understandings of professional philosophy that counter this proclivity. ${ }^{2}$

There are, however, points where Priest and I part company and these points of divergence are significant. For example and, perhaps, most significantly, Priest and I disagree on how our respective positions impose limitations on actual philosophical engagement. Where Priest's article, "What is Philosophy?", is specifically concerned with offering an account of philosophical engagement, my article, "How is this Paper Philosophy?", is concerned with values that orient the institutionalization of philosophical engagement. There is a fundamental difference between having one's analysis target the institutionalization of philosophical practice versus philosophical practice as such, a difference Priest acknowledges early in his reply [1]. However, this point of divergence is far more significant than Priest appears to appreciate. That is, a standard for a given practice functions very differently than a set of values aimed at orienting those standards. So, no, our accounts do not delimit in similar ways as

DOTSON, KRISTIE: Assistant Professor, Department of Philosophy, Michigan State University, USA. Email: dotsonk@msu.edu

\footnotetext{
${ }^{1}$ The page numbers of Priest's citation references in the current issue are given in bracket parentheses.

${ }^{2}$ Priest is also correct in pointing out that different geographical locations have different professional philosophy cultures. It is for this reason in my original paper and in this reply I will confine my remarks to professional philosophy in a U.S. context. As such, all references to professional philosophy refer to professional philosophy within the U.S.
} 
Priest claims, though we do both offer delimitations [8].

In what follows, I will briefly develop significant convergences and divergences between Priest's and my positions. The convergences illustrate a similar issue, i.e. lessening the effect of orthodoxy in professional philosophy, whereas the divergences illustrate a disagreement over the preferable strategy towards achieving this aim, i.e. the kind of delimiting strategy that would facilitate the lessening of orthodoxy. Ultimately, I indicate that when grappling with tendencies towards orthodoxy in a profession it is preferable to propose revisions at the level of institutionalization versus a standard at the level of practical engagement.

\section{THE YES:}

It should come as a surprise to no one that Priest is able to identify my paper, "How is this Paper Philosophy," as philosophy according to his own standard of philosophy as critique. I received my philosophy training in the U.S, where criticism is still the "life-blood of the discipline" (Priest 2006, 203n9). So to this observation, I can but shrug my shoulders, agree, and point to a reality that may be startling for some, though clearly not Priest. I am not a paradigmatic example of the many varied diverse practitioners that I am championing. Though I am a black woman employed in professional, academic philosophy in the U.S., I know I am not, by far, representative of the most diverse philosophical practitioners. ${ }^{3}$ And though I may represent diversity in professional philosophy in many respects, the same could not be said of all points where differences become salient. What this indicates is that what counts as diversity in professional philosophy is a complicated affair, which Priest demonstrates an appreciation for with his extension of my observations to paraconsistent logic [4-5].

Priest is also correct in identifying my problem with orthodoxy. Orthodoxy here is defined as gate-keeping that does not let in all legitimate traders. Priest calls this kind of gate-keeping "unhealthy." On this he and I agree [4]. I do have a problem with unhealthy gate-keeping or orthodoxy. We should all have a problem with orthodoxy, in my opinion, if for no other reason than, as Priest states, "orthodoxy is rarely right" [4]. In my paper, I attempt to demonstrate that professional philosophy in the U.S. shows the earmarks of a climate rife with unhealthy gate-keeping. ${ }^{4}$ Given that issues of diversity in professional philosophy are complicated and professional philosophy can be seen as riddled with orthodoxy, my project is to consider options for professional philosophical comportment that can address these two realities. As a result, I propose a shift in professional culture away from valuing narratives of legitimation to narratives of contribution, which I call a culture of praxis. ${ }^{5}$

\footnotetext{
${ }^{3}$ I think here of diverse practitioners like Africana philosophers Bill Lawson (2012), Leonard Harris (1997), Donna-Dale Marcano (2010), and John McClendon III (2012), to name a few, who all demonstrate diversity not only in their social identities, but in their methodologies, writing styles, and/or targeted research areas.

${ }^{4}$ See also (Dotson 2011).

${ }^{5} \mathrm{I}$ use the term praxis here in line with U.S. black feminist deployment of the term to refer to the ways our actions and practice are infused with beliefs, desires, and theoretical orientation, but also to
} 


\section{THE NO:}

There are two important points of divergence between Priest's position in his reply and his essay, "What is Philosophy?" and my paper, "How is this Paper Philosophy?" The first concerns the target of our inquiry, whereas the second concerns the kinds of delimitations our different accounts impose given our different targets. Priest, in answering the question, what is philosophy, offers a standard for philosophical engagement as such. In contrast, by inquiring into the question, how or in what manner a paper is philosophy, I propose a set of values that can orient the creation and application of standards for philosophical engagement. There is a difference between specifying philosophical engagement, i.e. proposing that philosophy is $x$, and orienting specifications of philosophical engagement, i.e. content and application of philosophical standards should accord with $x$ value. The former performs the task of determining what counts as philosophy, whereas the latter orients such standards. Priest in taking criticism to be a fundamental feature of philosophy, offers a filter standard on philosophy and philosophical engagement. Whereas I, as Bo Mou indicates, address "meta-methodological/meta-philosophical" issues for professional philosophy $(2012,1)$. I am not aiming at providing specifications for philosophy as such, but rather a set of values that can orient such specifications and their application. The values I propose have a specific aim, however. They aim to enable greater diversity within professional philosophy in the U.S by providing a means for addressing persisting orthodoxy. In accordance with this difference, Priest and my account do not delimit in similar ways.

By providing a filter standard on philosophy as such, Priest offers a criterion that can be used to judge whether something is a certain kind. ${ }^{6}$ When Priest explains that he takes "critique to be a defining feature of philosophy," he offers a filter standard for "philosophy" [8]. That is, what makes philosophy "philosophy" is critique. In contrast, I advocate a value and a point of recognition to orient standards for

understand the ways that even the most obscure ideas once adopted can affect our actions and lives. For many black feminists, our actions and contributions are theory producing insofar as they both orient and transform our theoretical understandings of the world (Collins 2000, Cooper 1992). And, in turn, our theories are actions producing (McClaurin 2001).

Now one would do well not to over simplify this orientation. It is not the case that every idea or inquiry needs to promote or encourage some specific course of action, though many theories do. Rather, it is an understanding that what questions become salient to us, what domains of inquiry prick our interests, or what kind of answers we seek do not emerge arbitrarily. They are often times pertinent to our, even if the "our" refers to "one's own," living. For example, I do not see the difference between "issues pertinent to our living" and "live matters" quite as clearly as Priest (p. 4-5). Even relatively obscure domains of inquiry are enabled by, at the very least, social conditions (e.g. the time and privilege to indulge in obscure inquiries), political conditions (e.g. the space to conduct one's inquiries), and personal interests that render live matters "live." In this vein, I see every inquiry as action in space, whether the inquiry recommends a particular action or not; and do not so clearly demarcate the difference between actions and theory production. I am not alone in this proclivity. It is a common U.S. Black feminist orientation, which, I admit, may have nothing in common with the Yugoslavian Praxis group (p4n6).

${ }^{6}$ This understanding of "filter standard" borrows heavily from (Whyte and Thompson 2010, 80). 
philosophy and the application of those standards. First, I advocate for a "value placed on seeking issues and circumstances pertinent to our living" for guiding the creation of standards themselves. Each issue and inquiry may have its own set of standards given the topic, audience, and goals of the research. Second, I urge "recognition and encouragement of multiple canons and multiple ways of understanding disciplinary validation" for the application of standards. This includes the recognition that if the actual contributions we make have certain demands for engagement, then not all standards are equally applicable to all forms of philosophical engagement and, hence, cannot be applied universally $(2012,17)$. These values, however, are not standards aimed at identifying philosophical engagement itself, i.e. what is philosophy.

To say that I am not offering a standard for philosophical engagement itself does not mean I am not proposing a standard. I may, and I concede Priest's point here, be offering a standard just the same. However, I am proposing a set of values that could act as a meta-standard, i.e. at the level of standards for philosophical engagement themselves. Hence, if a given standard does not demonstrate value placed on live matters and/or the application of a given standard does not include recognition of multiple canons and disciplinary validation, then it is not, according to my proposal, an appropriate standard, nor application of a standard for the institutionalization of philosophy. As such, the values I propose would impose restrictions. But they would restrict the creation and application of philosophical standards themselves. In this way, the set of values I propose would have an indirect effect on professional philosophical engagement, but they would not dictate precisely how philosophical engagement will manifest. The latter, I believe, is an unfortunate outcome of Priest's conception of philosophy as critique.

So though delimitations exist in both Priest and my respective accounts, they do not delimit in the same way. It would be inappropriate to ask of every philosophy paper or project, does your paper place a value on live matters and/or does it recognize multiple ways of disciplinary validation. It would be appropriate, in my estimation, to inquire after a standard for philosophical engagement and every application of philosophical standards in this fashion. The same cannot be said of Priest's understanding of philosophy as critique. It is unfortunate, though probably not intentional, that it would be appropriate to ask of every would-be philosophical paper or project if it includes or implies criticism. ${ }^{7}$ It would be, quite possibly, inappropriate to ask of every standard for philosophical engagement whether it includes or implies criticism. By placing restrictions on philosophy at the level of a philosophical practice, Priest and I are not playing the same game at all. His standard runs the risk of being taken as a universal, univocally relevant justifying norm for

\footnotetext{
${ }^{7}$ It is important to note that Priest does explain that every philosophical project does not have to be a critical one. He highlights the possibility of "a professional division of labour" between those who engage in critique and those who "who build the different views which make critique bite" (p.6 \& 2006, 206). However, that all aspects of philosophical engagement have to either offer a critique or imply a critique is still part of this conception of philosophy and is a particular orientation and strategy that may or may not be shared by all would-be philosophical practitioners.
} 
philosophical practice, which, if adopted, would most likely produce an orthodoxy that would exclude philosophical practitioners inspired by Audre Lorde, for example. This is an unacceptable outcome. I know several philosophical practitioners who are Lordeian in ways that make Priest's proposal unacceptable.

I openly concede that I am offering a delimiting standard, but it is a standard for standards. Hence, the difference in how our accounts offer restrictions is reflected in where our respective standards apply. Every project called "philosophy" would need to answer to Priest's standard of philosophy as criticism, if it were taken to orient all philosophical engagement. By contrast, every standard for philosophical engagement would need to comply with my evaluative standard. I am fine with this implication.

\section{THAT SAID...}

Do my remarks mean that Priest's account of philosophy as critique is horribly flawed? Not really. In fact, the differences between Priest's and my projects illustrate a point I wanted to press in my paper, "How is this Paper Philosophy?" Priest's account is not, by itself, problematic (Dotson 2012, 26). It only becomes problematic to the degree his understanding of philosophy as criticism is seen as a means for orienting the institutionalization of philosophy. It is a good description of some, quite possibly most, forms of philosophical engagement today. Should it be allowed to serve as a fundamental feature of all philosophical engagement, it would propagate "unhealthy" gatekeeping or orthodoxy [4] that would serve to quell important diversity, e.g. Lordean orientations. This observation does not appear to be incompatible with Priest's own intent. He explains that he never intended his understanding of philosophy to be "wielded by an entrenched and elite orthodoxy" ( $p$. 8). To stop this from happening, however, I propose we place Priest's account in perspective. It is not a universal standard. It is also compatible with my proposal for a culture of praxis. It is compatible with a value for contributing live issues and, as long as the interlocutor applying the standard is not overzealous, it is perfectly compatible with recognition of diverse canons and disciplinary validation. It is not a standard for all philosophical engagement, however. It is, as he explains, a part of philosophical engagement today that he takes to be more fundamental [8], though not every philosophical practitioner is going to agree with this, nor believe it their duty to critique it. And as long as we, professional philosophers, are sensitive to the places where his conception of philosophy is relevant and the places where it is not, then it strikes me Priest's conception does little harm and a great deal of good.

\section{REFERENCES}

Collins, Patricia Hill (2000), Black Feminist Thought: Knowledge, Consciousness, and the Politics of Empwerment (New York: Routledge).

Cooper, Anna Julia (1992), "Our Raison D'etre", in Charles Lemert \& Esme Bhan (eds.), The Voice of Anna Julia Cooper: Including a Voice from the South and 
Other Important Essays, Papers, and Letters (New York: Rowman and Littlefield), 109-120.

Dotson, Kristie (2011), "Concrete Flowers: Contemplating the Profession of Philosophy", Hypatia, 26 (2): 403-409.

Dotson, Kristie (2012), "How Is This Paper Philosophy?", Comparative Philosophy, 3 (1): 3-29.

Harris, Leonard (1997), "The Horror of Tradition or How to Burn Babylon and Build Benin While Reading Preface to a Twenty-Volume Suicide Note", in John P. Pittman (ed.) African-American Perspectives and Philosophical Traditions (New York: Routledge), 94-118.

Lawson, Bill (2012), "Philosophical Playa Hatin': Race, Respect, and the Philosophy Game", in George Yancy (ed.) Reframing the Practice of Philosophy: Bodies of Color, Bodies of Knowledge (Albany: SUNY Press), 181-199.

Marcano, Donna-Dale L. (2010), "The Difference That Difference Makes: Black Feminism and Philosophy", in Maria Del Guadalupe Davidson, Kathryn T. Gines \& Donna-Dale L. Marcano (eds.), Convergences: Black Feminism and Continental Philosophy (Albany: SUNY Press), 53-65.

Mcclaurin, Irma (2001), "Introduction: Forging a Theory, Politics, Praxis, and Poetics of Black Feminist Anthropology", in Irma Mcclaurin (ed.) Black Feminist Anthropology: Theory, Politics, Praxis, and Poetics (New Brunswick: Rutgers University Press), 1-23.

Mcclendon III, John (2012), "On the Politics of Profesional Philosophy", in George Yancy (ed.) Reframing the Practice of Philosophy: Bodies of Color, Bodies of Knowledge (Albany: SUNY Press), 121-146.

Mou, Bo (2012), "Editor's Words", Comparative Philosophy, 3 (2): 1-2.

Priest, Graham (2006), "What Is Philosophy?", Philosophy, 81: 189-206.

Whyte, Kyle Powys \& Thompson, Paul B. (2010), "A Role for Ethical Analysis in Social Research on Agrifood and Environmental Standards", Journal of Rural Social Sciences, 25 (3): 79-98. 